\title{
Structural Validity and Reliability of the Spanish Version of the White Bear Suppression Inventory (WBSI) in a Sample of the General Spanish Population
}

\author{
Manuel González Rodríguez, Pedro Avero Delgado, Anna Teresa Rovella, \\ and Rosario Cubas León \\ Universidad de la Laguna (Spain) \\ ${ }^{1}$ Universidad de San Luis (Argentina)
}

\begin{abstract}
This paper introduces the validation of the Spanish adaptation of the White Bear Suppression Inventory (WBSI) by Wegner and Zanakos (1994). A sample of 833 people from the general population completed the WBSI along with other questionnaires. The exploratory factor analysis and the confirmatory factor analysis supported a two-factor solution accounting for $51.8 \%$ of the cumulative variance. This structure is comprised of the two following factors: unwanted intrusive thoughts $(\alpha=.87, r=.70)$ and actions of distraction and suppression of thoughts $(\alpha=.80, \mathrm{r}=$ $.60)$. Both internal consistency reliability $(\alpha=.89)$ and test-retest reliability $(r=.71)$ showed adequate homogeneity, sound consistency, and stability over time. The results are discussed bearing in mind both isolated factors and the possible relationships of the suppression factor with automatic negative thoughts and insomnia.

Keywords: WBSI, ironic processes of mental control theory, thought suppression, reliability, validity, exploratory and confirmatory factor analyses, Spanish translation
\end{abstract}

Presentamos en este trabajo la validación de la adaptación española del White Bear Suppression Inventory (WBSI) (Inventario de Supresión del Oso Blanco) de Wegner y Zanakos (1994). A una muestra de 833 personas de la población general se le administró el WBSI conjuntamente con otros cuestionarios. Los análisis factoriales exploratorio y confirmatorio aconsejan la retención de una estructura bifactorial que explican el $51,8 \%$ de la varianza acumulada. Dicha estructura aísla pensamientos intrusos indeseados $(\alpha=0,87, r=0,70)$ y acciones de distracción y supresión de pensamientos $(\alpha=0,80, r=0,60)$. Los índices de consistencia interna del total del inventario $(\alpha=0,89)$ y fiabilidad test-retest $(r=0,71)$ muestran una adecuadas homogeneidad, sólida consistencia y una adecuada estabilidad temporal. Los resultados se discuten teniendo en cuenta los dos factores aislados y las posibles relaciones del factor de supresión con pensamientos automáticos negativos e insomnio.

Palabras clave: WBSI, teoría de los procesos irónicos de control mental, supresión de pensamientos, fiabilidad, validez, análisis factorial exploratorio y confirmatorio

Our sincere thanks to Professor Daniel Wegner from Harvard University for allowing us to use his inventory. Also, our sincere thanks to the three reviewers for their valuable contributions that allowed us to improve the original manuscript.

Correspondence concerning this article should be addressed to: Manuel González Rodríguez, Departamento de Personalidad, Evaluación y Tratamientos Psicológicos, Facultad de Psicología. Campus de Guajara, Universidad de La Laguna, 38205. Tenerife. Comunidad Autónoma de Canaria (Spain). Phone: +34 (922) 3174 65; +34 922316592 (Ext: 7465). Fax: +34 (922) 31 74 61. E-mail: mgonzaro@ull.es Translation: Virginia Navascués Howard.

How to cite the authors of this article: González Rodríguez, M., Avero Delgado, P., Rovella, A.T. and Cubas Leon, R. 
Thought flow frequently does not follow a logical, reasoned, foreseen, and goal-oriented trajectory. Thoughts are often related to unwanted cognitive activity that interferes with the capacity to generate functional thoughts and behaviors for people's normal adjustment (Sarason, Pierce, \& Sarason, 1996).

Unwanted intrusive thoughts (UIT) are very common in most people (Salkovskis, 1985). Thus, between $72 \%$ and $100 \%$ (mean 93\%) of people acknowledge they have this kind of intrusive thoughts (Rachman \& de Silva, 1978; Julien, O'Connor, \& Aardema, 2007), and that they are similar in form and content to obsessions (Clark \& Rhyno, 2005; Julien et al., 2007). Therefore, investigation of intrusive thoughts in the general population improves the ecological validity of its application in the clinical population. Intrusive thoughts can manifest in different types of cognitions, such as worries, ruminations, obsessive thoughts, attentional biases, digressions, memory lapses, and daydreaming (Kingler, 1996). This diversity of cognitive content allows us to identify the diverse cognitive processes or structures, and to differentiate them from another kind of clinically relevant cognitions (Clark \& Purdon, 1995).

Intrusive thoughts play a relevant role in many psychopathological disorders (Sarason et al., 1996). Hence, constantly maintaining such thoughts generates negative affect, causing people to seek strategies that can regulate, control, or avoid, not only intrusive thoughts, but also the general distress associated with them, and one of these strategies is thought suppression, which refers to how "the individual deals with emotional conflict or internal or external stressors by intentionally avoiding thinking about disturbing problems, wishes, feelings, or experiences" (American Psychiatric Association, 1994, p. 757). Another definition of thought suppression is "an effort not to think about something in particular and it means intentionally and voluntarily withdrawing attention from a thought, with special emphasis on the goal rather than on the strategies used to achieve it" (Wegner \& Zanakos, 1994).

The deliberate suppression of thoughts is a common form of mental control consisting of the attempt to eliminate or avoid persistent unwanted thoughts, and this effort leads to more intrusiveness (Wegner, 1989; Wegner \& Zanakos, 1994; Wenzlaff \& Luxton, 2003). This effect is explained by the theory of ironic processes of mental control, which establishes that suppression of unwanted intrusive thoughts has the paradoxical effect of increasing their frequency (Wegner, 1989, 1992, 1994; Wegner \& Zanakos, 1994; Wenzlaff \& Luxton, 2003). The initial experimental research of this theory began with the publication of the "white bear" experiment. In this study, an increase in the frequency of thoughts about white bears was observed if people tried to suppress them beforehand for a certain period of time. The authors concluded that suppression of unwanted thoughts leads to a paradoxical effect, that is, to a subsequent increase in their frequency (Wegner, Schneider, Carter, \& White, 1987).
Some authors suggest that this theory has a notable consequence on recent conceptualizations of emotional disorders characterized by the persistent repetition of intrusive thoughts, as they consider thought suppression a cognitive process related to the etiology and maintenance of diverse psychopathologies (Erber \& Wegner, 1996; Purdon, 1999; Purdon \& Clark, 2000; Purdon, Rowa, \& Anthony, 2005; Wegner \& Zanakos, 1994). Both experimental and correlational research in normal and clinical population have obtained results that confirm the theory of ironic processes (Abramowitz, Tolin, \& Street, 2001; Purdon \& Clark, 2000; Purdon et al., 2005; Rassin, Merckelbach, $\&$ Muris, 2000).

Due to the possible clinical implication in the theory of ironic processes, Wegner and Zanakos developed a 15-item self-report measurement, the White Bear Suppression Inventory (WBSI) to identify people who chronically use suppression as a strategy of mental control (Wegner \& Zanakos, 1994).

The WBSI was originally conceived as a one-factor measure (Muris, Merckelbach, \& Horselenberg, 1996; Wegner \& Zanakos, 1994) that explains $55 \%$ of the accumulated variance. In a recent work that used the item response theory, a reduced 6-item structure was isolated (items 3, 6, 9, 12, 13, and 15) with the same psychometric properties and relations with psychopathological measurements and emotional avoidance as the 15-item version (Palm \& Strong, 2007).

Other works report that the WBSI is bi-factor and yields a factor of intrusive thoughts and a factor of thought suppression that explain between $47.5 \%$ and $51.7 \%$ of the variance, with correlations between the factors ranging from .63 to .70 (Höping \& de Jong-Meyer, 2003; Luciano et al., 2006; Rassin, 2003). Thus, in a sample of students, two factors were obtained that explained $47.5 \%$ of the total variance, called Intrusive thoughts, $\alpha=.71$, and Thought suppression, $\alpha=.74$, with a correlation between the two factors of .70. And in a clinical sample, a bi-factor structure was also obtained, which explained $51.7 \%$ of the total variance, in which for the factor Intrusive thoughts, $\alpha=.84$; and for Thought suppression, $\alpha=.82$; and for the total score, $\alpha=.89$, with a correlation between the two factors of .63 (Rassin, 2003).

If we consider the WBSI a one-factor measure, the psychometric properties are adequate because internal consistency ranges between .88 and .91 . Regarding testretest reliability, various investigations have reported coefficients ranging from .69 to .92 over time intervals from 3 weeks to 3 months (Altin \& Gençöz, 2007; Fernández, Extremera, \& Ramos, 2004; Muris et al., 1996; Rassin \& Diepstraten, 2003; Wegner \& Zanakos, 1994). These data are consistent with the tendency to consider thought suppression a trait (Wegner \& Zanakos, 1994).

Regarding convergent and divergent validity, the WBSI has a correlation of between .44 and .45 with the Beck Depression Inventory (BDI-II; Beck, Steer, \& Brown, 1996); 
between .38 and .40 with the Maudsley ObsessionalCompulsive Inventory (MOCI; Hodgson \& Rachman, 1977), and between .49 and .58 with the STAI (State-Trait Anxiety Inventory de Spielberger, 1983) (Wegner \& Zanakos, 1994). Other works report coefficients of .57 with the STAI, .54 with the BDI, and 035 with the MOCI (Muris et al., 1996). In a more recent investigation, the WBSI was found to correlate at .50 with the BDI, and at .52 with the MOCI (Altin \& Gençöz, 2007).

Considering the WBSI as a bidimensional measurement, with regard to its convergent and divergent validity, the dimension of intrusive thoughts has a correlation of .44 with the BDI, .59 with the STAI, and .42 with the MOCI. However, the dimension of thought suppression has a correlation of $.15(p<.01)$ with the BDI, .11 (nonsignificant) with the STAI, and .11 (nonsignificant) with the MOCI (Höping \& de Jong-Meyer, 2003).

The previous results show higher convergent validity of the WBSI with depression and trait anxiety, and higher divergent validity with obsession-compulsion. In contrast, intrusive thoughts obtained higher convergent validity with trait anxiety, depression, and obsessions, and thought suppression obtained higher divergent validity with these same factors.

Of the works reviewed, one-factor and two-factor structures are defended the most: it is possible that the total WBSI score, considered a one-factor measurement - the most frequently used in investigations-not only reflects the tendency to suppress, but also to intrusion. Thus, if total scores on the inventory refer both to intrusive thoughts and to suppression, it is more difficult to interpret, because it is impossible to know whether low scores refer to people who suppress effectively or to people who do not experience intrusive thoughts and, consequently, have no wish to suppress them.

In any case, the factor structure of the test and its construct validity are unclear, and factors with similar names are not even defined by the same items. We therefore consider that to solve this issue is a priority so we can analyze in depth other psychometric properties of the inventory, such as its reliability (internal consistency and test-retest), as well as the differential-criterial validity, convergent, divergent, predictive, and discriminant validity of the inventory with regard to obsessive thoughts, depression, and cognitive processes such as intolerance of uncertainty and a meta-cognition (beliefs about worries).

\section{Method}

\section{Participants}

In this investigation, there were 833 participants, from two different samples of the Region of Canarias (Spain). The first sample comprised 502 people, of whom $58.7 \%$ were female and $41.3 \%$ were male. Their age ranged between 18 and 88 years $(M=29.10, S D=1.8)$. The second sample comprised 330 people, of whom $55.5 \%$ were female and $44.5 \%$ were male. Their age ranged between 18 and 74 years $(M=31.5, S D=12.2)$.

\section{Instruments}

The White Bear Suppression Inventory (WBSI; Wegner $\&$ Zanakos (1994). This inventory has 15 items with five response alternatives, ranging from 1 (totally disagree) to 5 (completely agree), which measure people's general tendency to suppress thoughts. The first factorization of the inventory was performed in 1998 (Ibáñez, Peñate, González, \& Cubas, 1998).

The Intolerance of Uncertainty Scale (IUS; Freeston, Rhéaume, Letarte, Dugas, \& Ladouceur, 1994). This scale has 27 items referring uncertainty, emotional, and behavioral reactions when faced with ambiguous situations. It has two factors, Uncertainty generating inhibition (cognitive, behavioral, and emotional) $-\alpha=.93, r=.65-$ and Uncertainty as disconcertion and imprevision $-\alpha=.89, r$ = .72-(González, Cubas, Rovella, \& Darias, 2006).

The questionnaire Why Worry? (WW?; Freeston et al., 1994). The 20-item questionnaire identifies people's focus of concern and allows them to rate the sentences. Internal consistency of the Spanish adaptation was $\alpha=.91$ with testretest reliability of $r=.76$. This questionnaire yields a factor of Worrying as a negative coping strategy, $\alpha=.86, r=.70$; and a factor of Worrying as positive perfectionism, $\alpha=.85$, $r=.75$ (González, Bethencourt, Fumero, \& Fernández, 2006).

The Padua Inventory (Sanavio, 1988). This is a 60-item inventory although, for this investigation, we only used 17 items from the Loss of control over mental activity factor, referring to items about obsessive thoughts and the lack of control over them. The internal consistency for this factor is $\alpha=.89$ (Ibáñez, Olmedo, Peñate, \& González, 2002).

The Beck Depression Inventory-II (BDI-II; Beck et al., 1996). We used the version of Sanz, Perdigón, and Vázquez (2003) and modified it to include the symptoms agitation, feelings of inadequacy, difficulty to concentrate, and loss of energy, that appear in the Diagnostic and Statistical Manual of Mental Disorders (4 ${ }^{\text {th }}$ ed.-TR; APA, 2000) as diagnostic criteria for depressive disorders. The internal consistency was $\alpha=.89$ (Sanz et al., 2003).

\section{Procedure}

Obtaining the two samples: The samples were randomly selected: 84 psychology students $(N=52$ for the first sample, and $N=32$ for the second) were trained in the administration of the above-mentioned tests to perform the role of assessors. These students should later select between 8 and 10 people from their near environment (the assessor's town neighbors, classmates, coworkers, etc.) to whom they applied the questionnaires. After contacting these people, the assessors informed them of the experimental nature of the work and 
asked them to complete the questionnaires, to hand in an informed consent, and provide a telephone number. The questionnaires were completed in the presence of the assessor, in an appropriate setting (at home, in an office, etc.) and guaranteeing the confidentiality of the information obtained. Five weeks later, 97 people completed the WBSI once again, along with other questionnaires.

\section{Statistical Analyses}

Exploratory factor analysis (EFA) was performed with the first sample. As the number of factors was indeterminate, we used the two most reliable procedures to determine the number of factors: the minimum average partial (MAP; Velicer, 1976) and parallel analysis (PA; Horn, 1965). In both cases, common factors are extracted and rotated by the oblimin procedure of the statistical package SPSS-14. Beforehand, only loadings higher than .30 (absolute value) are taken into account to define a factor.

Restrictive confirmatory factor analysis was performed with the second sample. Thus, the structures identified in our work and the solutions between one and three factors defended by various authors can be contrasted. These analyses were performed as a procedure of cross validation of our results, thus avoiding defining and contrasting a model with the same series of data (and favoring its confirmation). The models were identified by making the highest loading of each factor equal to 1 . These analyses were performed with the program AMOS 6.0.

\section{Results}

\section{Construct Validity. Exploratory and Confirmatory Factor Analysis}

The procedures used to determine the number of factors indicate either a one-factor (MAP) or a two-factor (PA) solution. The three-factor solutions are only defendable under the criterion of eigenvalues higher than 1 (Kaisers' rule), and there were no more factors that exceeded this criterion. The scree test also indicates retaining a maximum of two factors. The eigenvalues for these first three factors are: 6.10, 1.61, and 1.14 (40.7, 10.7 , and $7.5 \%$ explained variance, respectively).

The one-factor solution is mainly supported by the MAP, and by a factor on which all the items load over .40, with a mean item-total correlation of .59 , and a mean squared multiple correlation of .45. All these indicators support the unidimensionality of the inventory.

Alternately, the existence of two factors is supported by PA. All the items load on them over .30, explaining $51.8 \%$ of the total variance. In Table 1 , it can be seen that Factor 1 is made up of a total of 8 items that account for $42.2 \%$ of the variance. This factor seems to assess a series of recurrent thoughts and images that the person cannot avoid and that are difficult to control, so we called it Unwanted Intrusive Thoughts (UIT). The second factor is made up of 7 items that account for $9.6 \%$ of the total variance. This factor reflects people's desire to avoid certain thoughts and actions, or behaviors to distract them from such thoughts, and the attempt to suppress them, so we called it Actions to Distract and Suppress Thoughts (ADST). The mean squared multiple correlation for each factor was .44 and .39 , respectively. The mean item-total correlation was between .63 and .56 for each of the factors. All these indicators support the unidimensionality of each of the factors identified. The correlation between UIT and ADTS was .66, whereas their correlation with the total WBSI score was .93 and .89 , respectively.

Table 2 displays the goodness-of-fit indexes of the contrasted models. When contrasting isolated solutions with complex items, we decided to modify the model in order to assign the complex items to a single factor. These changes were carried out without taking into account the modification indexes, but rather, the magnitude of the loadings on the two factors (and their difference).

With this caveat, it is clear that no model adequately accounts for the data, as all of them are far from the recommended critical values for the fit indexes presented. The three-factor solution of Blumberg (2000) is also discarded because of the impossible values (correlations higher than 1). Despite this, the models reviewed show the poorest fit. The one-factor solution also seems clearly discardable. The two-factor solution of sample 2 (in boldface in Table 2) fits the best, independently of whether or not some complex items are considered. However, substantial considerations should be made when faced with the indetermination of statistical criteria.

The results included in a work that studies in detail the validity of the two- and three-factor solutions identified herein, along with the results of the current study, lead us to regard the two-factor structure as being more pertinent.

\section{Reliability Internal Consistency and Temporal Stability}

In Table 3, the internal consistency of each of the factors and of the total WBSI inventory can be observed with the following Cronbach's alpha values (which increase at retest): total WBSI: $\alpha=.89$; the factor UIT, $\alpha=0.87$; and for the factor ADTS, $\alpha=0.80$. Regarding test-retest reliability (after a 5-week interval), the following coefficients were obtained: $r=.70$ for the factor UIT, and $r=.60$ for the factor ADTS, and $r=.71$ for the total WBSI score. Although the correlation between the two time intervals was high, statistically significant differences (Student's $t$ ) were observed in the mean scores between these moments for UIT and for the total WBSI score, with retest scores being lower. This was not observed for the factor ADTS, so that the temporal stability of the WBSI may come more from the latter scores than from the former ones. 
Table 1

Sample 1. Exploratory Factor Analysis (Promax), Item-Total Correlation (r), Cronbach's Alpha without the Item( $\alpha$ ), Mean and Standard Deviation of each Item

\begin{tabular}{|c|c|c|c|c|c|c|c|}
\hline$\overline{\text { Items }}$ & UIT & ADTS & $h^{2}$ & $\bar{r}$ & $\alpha$ & $M$ & $S D$ \\
\hline 1. Hay cosas en las que prefiero no pensar. & & .43 & .31 & .47 & .89 & 3.7 & 1.1 \\
\hline 2. Algunas veces me pregunto por qué tengo estos pensamientos. & .59 & & .59 & .70 & .88 & 3.5 & 1.4 \\
\hline 3. Tengo pensamientos que no puedo evitar. & .77 & & .62 & .64 & .88 & 3.7 & 1.0 \\
\hline 4. Hay imágenes que me vienen a la mente y que no puedo eliminar. & .79 & & .66 & .67 & .88 & 3.2 & 1.3 \\
\hline 5. Mis pensamientos frecuentemente vuelven sobre la misma idea. & .78 & & .68 & .69 & .88 & 3.1 & 1.2 \\
\hline 6. Me gustaría poder dejar de pensar en ciertas cosas. & 60 & & .52 & .54 & .89 & 3.6 & 1.2 \\
\hline 7. Algunas veces mi mente va tan rápido que desearía poder pararla. & .52 & & .46 & .54 & .89 & 2.9 & 1.3 \\
\hline 8. Siempre trato de quitarme los problemas de la mente. & & .31 & .41 & .41 & .89 & 3.0 & 1.2 \\
\hline 9. Hay pensamientos que me vienen una y otra vez a la cabeza. & .80 & & .65 & .62 & .88 & 3.4 & 1.1 \\
\hline 10. Hay cosas en las que trato de no pensar. & & .48 & .54 & .54 & .89 & 3.6 & 1.0 \\
\hline 11. Algunas veces me gustaría dejar de pensar. & & .36 & .53 & .53 & .89 & 2.9 & 1.3 \\
\hline 12. A menudo hago cosas para distraerme de mis pensamientos. & & .82 & .60 & .60 & .89 & 3.2 & 1.2 \\
\hline 13. Tengo pensamientos que trato de evitar. & & .47 & .71 & .71 & .88 & 3.3 & 1.1 \\
\hline 14. Tengo muchos pensamientos que no cuento a nadie. & .30 & & .47 & .47 & .88 & 3.6 & 1.2 \\
\hline $\begin{array}{l}\text { 15. Algunas veces me mantengo ocupado para evitar que me vengan } \\
\text { pensamientos a la cabeza. }\end{array}$ & & .79 & .58 & .58 & .89 & 3.0 & 1.3 \\
\hline Eigenvalue & 6.3 & 1.4 & & & & & \\
\hline$\%$ total variance & 42.2 & 9.6 & & & & & \\
\hline$\%$ accumulated variance & 42.2 & 51.8 & & & & & \\
\hline Correlation between WBSI factors - total WBSI score & .93 & .89 & & & & & \\
\hline Correlation between factors UIT-ADTS & .66 & & & & & & \\
\hline
\end{tabular}

Note. UIT = unwanted intrusive thoughts, ADST = actions of distraction and thought suppression.

[Translator's note: The items have not been translated because this is the Spanish version of a scale originally published in English.]

Table 2

Fit indexes for the models contrasted and for Sample 2

\begin{tabular}{llcccccc}
\hline Models/Indexes & $\chi$ & $d f$ & SRMR & TLI & CFI & RMSEA \\
\hline 1 Factor & & 467 & 90 & .119 & .756 & .791 & .120 \\
2 Factors & Rassin-12 & 256 & 53 & 113 & .805 & .844 & .115 \\
& Höping-15 & 413 & 89 & .125 & .788 & .820 & .112 \\
$\mathrm{x}$ & Höping-14 & 413 & 76 & .119 & .841 & .867 & .098 \\
$\mathrm{x}$ & Sample 2 & $\mathbf{3 1 4}$ & $\mathbf{8 7}$ & $\mathbf{. 0 9 5}$ & $\mathbf{. 8 4 8}$ &. $\mathbf{8 7 4}$ &. $\mathbf{0 9 5}$ \\
& Sample 2-11(1) & 325 & 88 & .098 & .843 & .869 & .096 \\
& Sample 2-13(2) & 342 & 89 & .102 & .834 & .859 & .099 \\
3 Factors & Blumberg (*) & 320 & 87 & .100 & .844 & .871 & .096 \\
& Sample 2 & 329 & 87 & .109 & .838 & .866 & .098 \\
& Sample 2 13(3) & 313 & 86 & .111 & .846 & .874 & .095
\end{tabular}

Note. (*) Inadmissible solution, correlation matrix between factors not positive. Höping-15: all the items define the model; Höping-14: a 14-item model (loadings higher than .30). Sample 2 (2 factors): items 11 and 13 are complex. Sample 2-11(1): item 11 assigned to Factor 1. Sample 2-13(2): item 13 assigned to Factor 2 (and item 11 to Factor 1). Sample 2-12(3): Item 13 assigned to Factor 3. GFI = goodness of fit index ; AGFI = adjusted goodness of fit index; SRMR = standardized root mean square residual; TLI = Tucker-Lewis index; $\mathrm{CFI}=$ comparative fit index; RMSEA = Root mean square error of approximation. 
Table 3

Means, Standard Deviations (in brackets), Student's $t$, Test-retest reliability coefficient ( $r$ ) in the two Factors and the Total WBSI Score, and internal consistency coefficient (Cronbach's $\alpha$ )

\begin{tabular}{lcccccccccc}
\hline & & & & & & \multicolumn{4}{c}{ Gender } \\
& Test & Retest & & & $\alpha$ (test) & $\alpha$ (retest) & Women & Men & $t$ & Total sample \\
& $M(S D)$ & $M(S D)$ & $t$ & $r$ & $N=833$ & $N=97$ & $M(S D)$ & $M(S D)$ & $M(S D)$ \\
\hline UIT & $26.9(6.9)$ & $25.2(8.6)$ & $2.66^{* *}$ & $.70^{* * *}$ & .87 & .92 & $27.0(6.5)$ & $25.3(7.5)$ & $2.67 * *$ & $26.2(6.8)$ \\
ADTS & $22.4(5.8)$ & $21.5(6.6)$ & $1.65(n s)$ & $.60^{* * *}$ & .80 & .83 & $23.5(5.3)$ & $21.3(5.7)$ & $2.89^{* *}$ & $22.5(5.5)$ \\
WBSI & $49.0(11.7)$ & $46.5(14.5)$ & $2.38^{*}$ & $.71^{* * *}$ & .89 & .93 & $50.7(10.7)$ & $47.0(11.5)$ & $2.86^{* *}$ & $49.0(11.2)$ \\
\hline
\end{tabular}

Note. UIT $=$ Unwanted intrusive thoughts; ADTS = Actions of distraction and thought suppression; WBSI = total WBSI score.

$* p<.05 . * * p<.01 . * * * p<.001$.

\section{Convergent and Divergent Validity}

As another detail in the study of the WBSI, we carried out a zero-order correlational analysis on loss of control over mental activity, intolerance of uncertainty, metacognitions about worry (from the WW?), and depression (BDI-II). The coefficients were transformed into $z$-scores to allow contrasting the means of the correlation coefficients obtained.

In Table 4, it can be observed that the factor UIT was related to psychopathological variables, where the correlation coefficient with loss of control over mental activity-obsession was .61, whereas the factor ADTS had a correlation of .40. In contrast, loss of control over mental activity (obsession) had a correlation of $.58(33.6 \%)$ with the total WBSI score. The correlation coefficients showed statistically significant differences between UIT and ADTS, but not between UIT and the total WBSI (in boldface in Table 4). The BDI-II (depression), had a correlation of .52 with UIT, and of .37 with loss of control over mental activity, and the differences between these correlation coefficients were statistically significant.

Regarding the process variables of intolerance of uncertainty and beliefs about worry, the relations with UIT and ADTS were different. For the total score of the IUS and its two factors (Uncertainty generating inhibition and Uncertainty as disconcertion and imprevision), the correlation coefficients with UIT were higher than .40; however, the correlation coefficients with ADTS were around .40. With regard to the total WW? questionnaire (beliefs about worry or meta-cognition), the correlation coefficient with UIT was higher and statistically significant $(r=.47)$, whereas with ADTS, it was .34. Regarding the two factors of the WW? questionnaire, Worrying as a negative coping strategy had correlations of .50 and .38 with UIT and ADTS, respectively, whereas Worrying as positive perfectionism presented correlations of .34 and .23 with UIT and ADTS, respectively (see Table 4).

These latter results suggest that the process of intolerance of uncertainty is related both to UIT and ADTS. However, the meta-cognition of worrying as a negative coping strategy is more closely related to UIT $(r=.50)$ than to worrying as positive perfectionism $(r=.34)$.

As a higher correlation was observed between the WBSI and loss of control over mental activity (obsession) than between the WBSI and the BDI-II (depression) and intolerance of uncertainty, we wished to know whether the correlation coefficient between these two constructs, (WBSI and obsession) was independent of depression and intolerance of uncertainty, as the latter was equally relevant to both WBSI factors. Therefore, we calculated a partial Person's correlation. In Table 4, it can be seen that, if the combined effect of the BDI-II and intolerance of uncertainty is controlled, the correlation between the two factors (UIT and ADTS) and the WSBI with loss of control over mental activity decreases (explaining 17.6\%, 13.7\%, and $1.9 \%$, respectively, of the variance). We also note that the relation between the score in loss of control over mental activity and the WBSI is sensitive to the impact of mood and intolerance of uncertainty, and the effect for ADTS was higher.

The statistically significant differences between the two WBSI factors and loss of control over mental activity, found both in the zero-order correlation coefficients and the partial correlation coefficients, indicates that despite UIT, people do not suppress such thoughts in a way directly proportional to the intrusions. So, we attempted to determine whether low scores in the WBSI factor UIT refers to people who suppress effectively or to people who have no UIT and, therefore, have no wish to suppress them. For this purpose, we graphically represented the values of the mean scores (in $z$-scores) of the criterial groups as a function of high and low scores in loss of control over mental activity (obsession). The first group $(N=139)$ is made up of those who scored low (score equal to or lower than percentile 25), and the second group $(N=128)$, those who scored high (score equal to or higher than percentile 75).

Figure 1 shows that the group with low scores in loss of control over mental activity (obsession) also obtained low scores in UIT and ADTS, and the differences between 
Table 4

Correlations among Loss of Control over Mental Activity, Intolerance of Uncertainty, and BDI-II-Depression Scores with Unwanted Intrusive Thoughts and Actions of Distraction and Thought Suppression

\begin{tabular}{|c|c|c|c|c|c|}
\hline \multicolumn{2}{|c|}{ Zero-order correlation } & \multirow{2}{*}{$\frac{\text { UIT }}{.61 * * * *}$} & \multirow{2}{*}{$\begin{array}{r}\text { ADTS } \\
\mathbf{4 0} * * * *\end{array}$} & \multirow{2}{*}{$\frac{\text { WBSI }}{.58 * * * *}$} & \multirow{2}{*}{$\frac{\mathrm{z}}{5.53 * * *}$} \\
\hline$N=755$ & LCMA & & & & \\
\hline & IUS & $.49 * * * *$ & $.42 * * * *$ & $.50 * * * *$ & $1.71 n s$ \\
\hline & UGI & $.49 * * * *$ & $.42 * * * *$ & $.50 * * * *$ & $1.71 \mathrm{~ns}$ \\
\hline & UDI & $.44 * * * *$ & $.37 * * * *$ & $.45 * * * *$ & $1.62 n s$ \\
\hline & WW? & $.47 * * *$ & $.34 * * *$ & $.45^{* * *}$ & $2.69 * *$ \\
\hline & WNCS & $.50 * * *$ & $.38 * * *$ & $.49 * * *$ & $2.57 * *$ \\
\hline & WPP & $.34 * * *$ & $.23 * * *$ & $.32 * * *$ & $2.07 *$ \\
\hline & BDI-II & $.52 * * * *$ & $.37 * * * *$ & $.50 * * * *$ & $3.64 * * *$ \\
\hline \multicolumn{6}{|c|}{ Partial correlations between LCMA and WBSI } \\
\hline \multicolumn{3}{|c|}{ Controlling the effect of: } & & & $z$ \\
\hline$N=694$ & BDI & $.43^{* * *}$ & $.25 * * *$ & $.39 * * *$ & $3.67 * * *$ \\
\hline$N=677$ & IUS & $.43^{* * * *}$ & $.19 * * *$ & $.36 * * *$ & $4.81 * * *$ \\
\hline$N=656$ & BDI-II \& IUS & $.37 * * * *$ & $.15 * *$ & $.30 * * * *$ & $4.26 * * *$ \\
\hline
\end{tabular}

Note $:$ UIT = Unwanted intrusive thoughts; ADTS = Actions of distraction and thought suppression; WBSI = Total WBSI score;

LCMA = Loss of control over mental activity; IUS = Intolerance of Uncertainty Scale; UGI = uncertainty generating inhibition; UDI $=$ uncertainty as disconcertion and improvisation. WW = Why worry?; WNCS = Worrying as negative coping strategy; WPP = Worrying as positive perfectionism; BDI-II = Beck Depression Inventory-II.

Boldeface represents statistically significant differences between the first and second factor.

$* * p<.01 . * * * * p<.0009$.

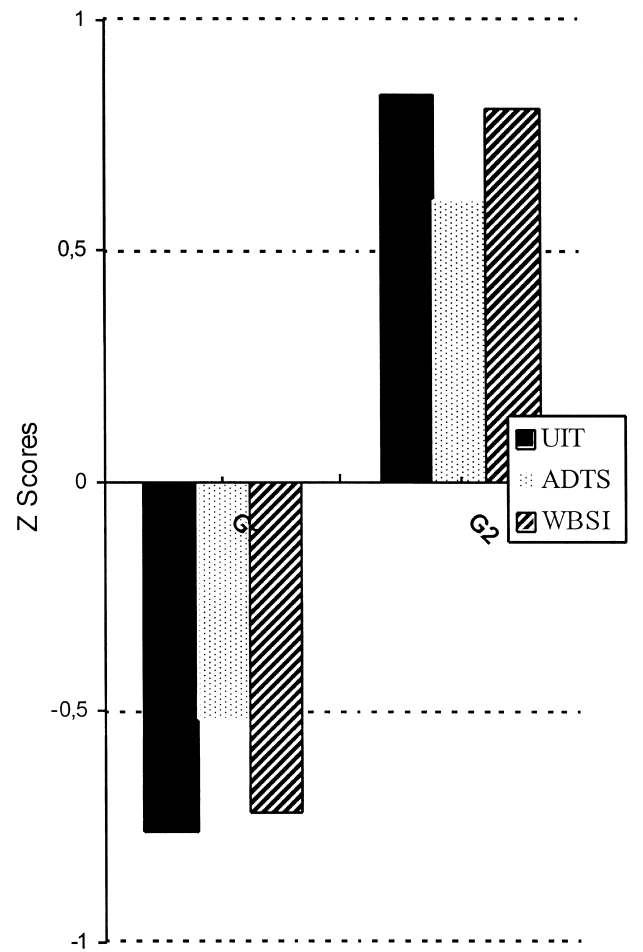

Figure 1. Value of mean WBSI scores and the two factors (UIT and ADTS) as a function of the groups with low (G1) and high (G2) scores in Loss of control over mental activity. UIT = Unwanted intrusive thoughts. ADTS = Actions of distraction and thought suppression. WBSI = White Bear Supression Inventory. these two factors (UIT and ADTS) were statistically significant $(p<.001)$. However, these differences were not observed between UIT and the total WBSI score, thus confirming that people who obtain low scores in loss of control over mental activity (obsession) do not wish to suppress. People who scored high in loss of control over mental activity (obsession) are characterized by scoring higher in both factors (UIT and ADTS) and in the total WBSI score. The differences between the two factors were statistically significant $(p<.0001)$, indicating that despite high scores in loss of control over mental activity (obsession), a directly proportional relation to attempts of suppression was not observed. This is plausible because suppression is a dysfunctional strategy, and so, these data respond to the issues proposed at the beginning of this work.

\section{Differential-Criterial Validity of the Items}

All the items and factors of a psychometric test should have differential-criterial validity. For this purpose, we performed a difference of means with Student's $t$ test for independent samples.

With regard to the criterion group, all the comparisons were significant for both factors and items, except for Item 1. That is, all the items (except for Item 1) differentiated between high and low scorers in loss of control over mental activity (obsession). Therefore, with regard to the criterion used, the differential-criterial validity of the test is adequate. 


\section{Predictive Validity}

Subsequently, using the two WBSI factors and other process variables (the two Intolerance of Uncertainty factors and the WW?) as predictors and loss of control over mental activity (obsession) as the criterion, we performed multiple regression analysis. We used the stepwise method in order to maximize knowledge about the relative contribution of each process. In Table 5, it can be seen that three variables help to predict the score in loss of control over mental activity-obsession, and account for 58\% of the common variance. If we take into account that, regarding the semipartial squared correlation, UIT contributes the most (6.2\%) to the explanation of loss of control over mental activity (obsession), followed by the uncertainty that generates inhibition (cognitive, behavioral, and emotional), which explains $4.8 \%$ of the variance, and the meta-cognition of worrying as a negative coping strategy $(2.8 \%$ of the variance). The factor worrying as positive perfectionism and ADTS are excluded from the predictive model.

\section{Discussion}

In this investigation, we presented the results of the Spanish validation of the White Bear Suppression Inventory (WBSI; Wegner \& Zanakos (1994), in which we studied in depth its factor structure, content validity, and convergent and discriminant validity. Thus, the exploratory and the confirmatory factor analyses support a structure with two highly related factors, although they may also be two different constructs. We called the first factor Unwanted intrusive thoughts (UIT) and the second one actions of distraction and thought suppression (ADTS), along the lines of previous investigations (Höping \& de Jong-Meyer, 2003; Rassin, 2003).

The psychometric properties of the two factors are satisfactory and very similar to those in the reviewed investigations (Höping \& de Jong-Meyer, 2003; Rassin, 2003). But with regard to test-retest reliability, it should be noted that, although our results provide evidence that the UIT and the total WBSI score present statistically significant differences between the two time intervals ( 5 weeks), and if we take into account the cross-temporal and crosssituational consistency, this means that UIT are very consistent, but there is some cross-temporal lability. This implies that the people's consideration of the possibility of thought suppression may vary from time to time, but when it varies, this change affects all the contents of the suppression equally. That is, thought suppression as a trait, as defended by Wegner (Wegner \& Zanakos, 1994), may come more from attempts to suppress than from thought intrusion itself.

With regard to convergent validity, we observed that UIT are highly related to loss of control over mental activity (obsession) and the BDI-II (depression), as well as to a meta-cognition related to the generalized anxiety disorder, worrying as a negative coping strategy. In contrast, ADTS shows high divergent validity with the aforementioned disorders (obsession. depression, and worrying as a negative coping strategy), and also with worrying as positive perfectionism.

The partial correlations modulated the relations of loss of control over mental activity (obsession) with the two WBSI factors when the effects of depression and intolerance of uncertainty are controlled, a result that is in accordance with the theoretical models of the obsessive-compulsive disorder, in which intolerance of uncertainty and metacognitive processes are beginning to be considered variables of causal cognitive vulnerability to obsessions (Farell \& Barret, 2006; González, Ibáñez, \& Cubas, 2006; Tolin, Abramowitz, Brigidi, \& Foa, 2003). In this sense, people with high scores in obsession do not use thought suppression as a strategy to control obsessions, but rather the obsession is maintained because of a dysfunctional meta-cognitive belief, such as worrying as a negative coping strategy. The latter, together with intolerance of uncertainty and other dimensions, are two meta-cognitive and cognitive constructs proposed by the Obsessive-Compulsive Cognitions Work Group (OCCWG, 2001), and they are also related to other anxiety and mood disorders (González, Ibáñez, et al., 2006).

If one's mood and intolerance of uncertainty increase intrusive thoughts and, consequently, the attempts to control by suppression fail, there is an increase in the negative appraisal of the meaning of the thought, which somehow increases the levels of intolerance of uncertainty, depression, and anxiety,

Table 5

Multiple Regression Analysis of the LCMA-Obsession Score

\begin{tabular}{lclccc}
\hline Criterion & Independent Variables & $\beta$ & Adjusted $R^{2}$ & $t$ & $s r^{2}$ \\
\hline LCMA & UGI & .33 & .45 & $6.88^{* * *}$ & .048 \\
& UIT & .35 & .55 & $7.94 * * *$ & .062 \\
& WNCS & .25 & .58 & $5.46^{* * *}$ & .028 \\
\hline
\end{tabular}

Note $:$ LCMA = Loss of control over mental activity; UGI = Uncertainty generating inhibition; UIT = Unwanted intrusive thoughts; WNCS $=$ Worrying as negative coping strategy.

$* p<.05 . * * p<.01 . * * * p<.001$. 
thus making real control of thoughts very difficult (Tolin, Abramowitz, Przeworski, \& Foa, 2002), and, consequently, this failure increases the levels of anxiety and negative affect (Tolin, Abramowitz, Hamlin, Foa, \& Synodi, 2002).

In this sample, the mean score of UIT was $26.2(S D=$ $6.8)$ and of ADTS, $22.5(S D=5.5)$. In a clinical sample of 44 patients referred by primary care doctors for some anxiety or mood disorder, we found that intrusive thoughts obtained a mean of $33.85(S D=5.38)$ and ADTS, $27.46(S D=5.38)$ (González et al., 1998). The mean scores of the WBSI are lower than those found by some authors (Blumberg, 2000; Wegner \& Zanakos, 1994). However, our results, both in the normal and clinical samples revealed higher and statistically significant mean scores $(p<.001)$ than those found in previous investigations (Rassin, 2003).

From the above results, it is concluded that even people with high scores in loss of control over mental activity (obsession) do not use thought suppression and this may be because suppression is a dysfunctional strategy to control worrying thoughts or that people have learned negative expectations because of this lack of effectiveness of suppression. Despite this, a meta-cognition-worry as a negative coping strategy-seems constant when faced with thoughts of loss of control over mental activity (obsession). This attempt to control thoughts somehow reinforces the obsession negatively and it is just as dysfunctional as ADTS.

In the last 21 years, research on thought suppression has increased considerably, perhaps because suppression is not simply an ineffective strategy of mental control (Blumberg, 2000; Nagtegaal \& Rassin, 2004; Purdon, 1999; Wenzlaff \& Luxton, 2003), but also because deliberate suppression strategies promote a deficit in the normal habituation of intrusive thoughts (Purdon \& Clark, 2001). In this sense, future research should use the two WBSI factors because UIT could be used by clinical psychologists as a preventive and causal measure of diverse anxiety and mood disorders, whereas ADTS could be more related to negative automatic thoughts and insomnia. Longitudinal studies should be carried out to cast light on whether the suppression strategies are the cause or the effect of diverse psychopathologies and on the differential relations of each factor found in this investigation with psychopathological dimensions and the clinical implications and relative merits of alternative strategies, such as correct or functional suppression.

\section{References}

Abramowitz, J. S., Tolin, D. F., \& Street, G. P. (2001). Paradoxical effects of thought suppression: A meta-analysis of controlled studies. Clinical Psychology Review, 21, 683-703.

Altin, M., \& Gençöz, T. (2007). Persistence of obsessive compulsive symptoms: similarities and contrasts with symptoms of depression in a Turkish sample. Behaviour Change, 24, 146156.
American Psychiatric Association (1994). Diagnostic and Statistical Manual of Mental Disorders (4 ${ }^{\text {th }}$ ed.). Washington, DC: Author.

American Psychiatric Association (2000). Diagnostic and Statistical Manual of Mental Disorders ( $4^{\text {th }}$ ed.- TR). Washington, DC: Author.

Beck, A.T., Steer, R.A., \& Brown, G. K. (1996). Manual for the Beck Depression Inventory-II. San Antonio, TX: Psychological Corporation.

Blumberg, S. J. (2000). The White Bear Suppression Inventory: Revisiting its factor structure. Personality and Individual Differences, 29, 943-950.

Clark, D. A., \& Purdon, C. (1995). The assessment of unwanted intrusive thoughts: A review and critique of the literature. Behaviour Research and Therapy, 33, 967-976.

Clark , D. A., \& Rhyno, S. (2005). Intrusive thoughts in clinical disorders: Theory, research, and treatment. In David A. Clark (Ed.). Unwanted intrusive thoughts in nonclinical individuals: Implications for Clinical Disorders. New York: Guilford Press.

Erber, R., \& Wegner, D. M. (1996). Ruminations on the rebound. In R. S. Wyer, Jr. (Ed.), Ruminative thoughts. Advances in social cognition (pp. 73-79). Mahwah, NJ: Erlbaum.

Farell, L., \& Barrett, P. (2006). Obsessive-compulsive disorder across developmental trajectory: Cognitive processing of threat in children, adolescents and adults. British Journal of Psychology, 97, 95-114.

Fernández, B. P., Extremera, N., \& Ramos, N. (2004). Validity and reliability of the Spanish version of the White Bear Suppression Inventory. Psychological Report, 94, 782-784.

Freeston, M. H., Rhéaume, J., Letarte, H., Dugas, M. J., \& Ladouceur, R. (1994). Why do people worry? Personality and Individual Differences, 17, 791-802.

González, M., Bethencourt, J. M., Fumero, A., Fernández, A. (2006). Adaptación española del cuestionario ¿Por qué preocuparse? Psicothema, 18, 313-318.

González, R, M., Cubas, L. R., Rovella, A. T., \& Darias, H. M. (2006). Adaptación española de la Escala de Intolerancia hacia la Incertidumbre: procesos cognitivos, ansiedad y depresión. Psicología y Salud,16, 219-233.

González, M., Ibáñez, I., Cubas, R. (2006). Variables de proceso en la determinación de la ansiedad generalizada y su generalización a otras medidas de ansiedad y depresión, International Journal of Clinical and Health Psychology, 6, 23-39.

González, M, Ibañez, I., Diaz, M.C., Fernández-Valdés, A., LópezCurbelo, M., \& Díaz, F. (1998). Dimensiones psicológicas implicadas en el trastorno de ansiedad generalizada (TAG): Implicaciones para un tratamiento psicológico eficiente. Informe Técnico. Mimeo. Universidad de La Laguna (Spain).

Hodgson, R. J., \& Rachman, S. (1977). Obsessional-compulsive complaints. Behaviour Research and Therapy, 15, 389-395.

Höping, W., \& de Jong Meyer, R. (2003). Differentiating unwanted intrusive thoughts from thought suppression: What does the White Bear Suppression Inventory measure? Personality and Individual Differences, 34, 1049-1055.

Horn, J. L. (1965). A rationale and test for the number of factors in factor analysis. Psychometrica 30, 179-185. 
Ibáñez, I., Peñate, W., González, M., \& Cubas, R. (1998). El Inventario de Supresión de Pensamientos (WBSI): Validación española. III Congreso Iberoamericano de Psicología de la Salud. In L.E. Ferrer (Comps.) (1998). Programa y Libro Resúmenes. Torremolinos, Spain: AEPC, 63.

Ibáñez, I., Olmedo, E., Peñate, W., \& González, M. (2002). Obsesiones y compulsiones: la estructura del Inventario de Padua. International Journal of Clinical and Health Psychology, 2, 263-288.

Julien, D., O'Connor, K. P., \& Aardema, F. (2007). Intrusive thoughts, obsessions, and appraisals in obsessive-compulsive disorder: A critical review. Clinical Psychology Review, 27, 366-383.

Klinger, E. (1996). The contents of thoughts: Interference as the downside of adaptive normal mechanisms in thought flow. In I. G. Sarason, G. R. Pierce, \& B. R. Sarason (Eds.), Cognitive interference: Theories, methods, and findings (pp. 3-23). Mahwah, NJ: Erlbaum.

Luciano, J.V., Belloch, A., Algarabel, S., Tomás, J.M., Morillo, C., \& Lucero, M. (2006). Confirmatory factor analysis of the White Bear Suppression Inventory and the Thought Control Questionnaire: A comparison of alternative models. European Journal of Psychological Assessment, 22, 250-258.

Muris, P., Merckelbach, H., \& Horselenberg, R. (1996). Individual differences in thought suppression. The White Bear Suppression Inventory: Factor structure, reliability, validity and correlates. Behaviour Research and Therapy, 3, 501-513.

Nagtegaal, M. H., \& Rassin, E. (2004). The usefulness of the thought suppression paradigm in explaining impulsivity and aggression. Personality and Individual Differences, 37, 1233-1244.

Obsessive Compulsive Cognitions Working Group (2001). Development and initial validation of the Obsessive Beliefs Questionnaire and the Interpretation Intrusions Inventory. Behaviour Research and Therapy, 39, 987-1005.

Palm, K. M., \& Strong, D. R. (2007). Using item response theory to examine the White Bear Suppression Inventory. Personality and Individual Differences, 42, 87-98.

Purdon, C. (1999). Thought suppression and psychopathology. Behaviour Research and Therapy, 37, 1029-1054.

Purdon, C., \& Clark, D. A. (2000). White bears and other elusive intrusions: Assessing the relevance of thought suppression for obsessional phenomena. Behavior Modification, 24, 425-453.

Purdon, C., \& Clark, D. A. (2001). Suppression of obsession-like thoughts in nonclinical individuals: Impact on thought frequency, appraisal and mood state. Behaviour Research and Therapy, 39, 1163-1181.

Purdon, C., Rowa, K., \& Antony, M. M. (2005). Thought suppression and its effects on thought frequency, appraisal and mood state in individuals with obsessive-compulsive disorder. Behaviour Research and Therapy, 43, 93-108.

Rachman, S., \& de Silva, P. (1978). Abnormal and normal obsessions. Behaviour Research and Therapy, 16, 233-248.

Rassin, E. (2003). The White Bear Suppression Inventory (WBSI) focuses on failing suppression attempts. European Journal of Personality, 17, 285-298.
Rassin, E., \& Diepstraten, P. (2003). How to suppress obsessive thoughts. Behaviour Research and Therapy, 41, 97-103.

Rassin, E., Merckelbach, H., \& Muris, P. (2000). Paradoxical and less paradoxical effects of thought suppression: A critical review. Clinical Psychological Review, 20, 973-995.

Salkovskis, P. M. (1985). Obsessional-compulsive problems: A cognitive-behavioural analysis. Behaviour Research and Therapy, 23, 571-584.

Sanavio, E. (1988). Obsessions and compulsions: The Padua Inventory. Behaviour Research and Therapy, 26, 169-177.

Sanz, J., Perdigón, A. L., \& Vázquez, C. (2003). Adaptación española del Inventario para la Depresión de Beck-II (BDIII): propiedades psicométricas en población general. Clínica y Salud, 14, 249-280.

Sarason, I. G., Pierce, G. R., \& Sarason, B. R. (1996). Domains of cognitive interference. In I. G. Sarason, G. R. Pierce, \& B. R. Sarason (Eds.), Cognitive interference: Theories, methods and findings (pp. 139-152). Mahwah, NJ: Erlbaum.

Spielberger, C. D. (1983). State-Trait Anxiety Inventory. Palo Alto, CA: Consulting Psychologists Press.

Tolin, D. F., Abramowitz, J. S., Hamlin, C., Foa, E. B., \& Synodi, D. S. (2002). Attributions for thought suppression failure in obsessive-compulsive disorder. Cognitive Therapy and Research, 26, 505-517.

Tolin, D. F., Abramowitz, J. S., Brigidi, B. D., \& Foa, E. B. (2003). Intolerance of uncertainty in obsessive-compulsive disorder. Journal of Anxiety Disorders, 17, 233-242.

Tolin, D. F., Abramowitz, J. S., Przeworski, A., \& Foa, E. B. (2002). Thought suppression in obsessive-compulsive disorder. Behaviour Research and Therapy, 40, 1255-1274.

Velicer, W. F. (1976). Determining the number of components from the matrix of partial correlations. Psychometrica 41, 321-327.

Wegner, D. M. (1989). White bears and other unwanted thoughts, suppression, obsession, and the psychology of mental control. New York: Viking.

Wegner, D. M. (1992). You can't always think what you want: Problems in the suppression of unwanted thoughts. In M. Zanna (Ed.). Advances in experimental social psychology (Vol. 25). San Diego: Academic Press.

Wegner, D. M. (1994). Ironic processes of mental control. Psychological Review, 101, 34-52.

Wegner, D. M., Schneider, D. J., Carter, S. R., \& White, T. L. (1987). Paradoxical effects of thought suppression. Journal of Personality and Social Psychology, 53, 5-13.

Wegner, D. M., \& Zanakos, S. (1994). Chronic thought suppression. Journal of Personality, 62, 615-640.

Wenzlaff, R. M., \& Luxton, D. D. (2003). The role of thought suppression in depressive rumination. Cognitive Therapy and Research, 27, 293-308.

Received July 5, 2007

Revision received April 6, 2008 Accepted April 25, 2008 